The Role of Theory of Mind and Wishful Thinking in Children's Moralizing Concepts of the Abrahamic God

Redeate G. Wolle, ${ }^{\mathrm{a}}$ Abby McLaughlin, ${ }^{\mathrm{b}}$ and Larisa Heiphetz ${ }^{\mathrm{c}}$

${ }^{a}$ Department of Psychology, Columbia University. 1190 Amsterdam Ave., New York, NY 10027, United States. E-mail: rgw2121@columbia.edu. Phone: 212-853-1407.

${ }^{\mathrm{b}}$ Department of Psychology, Columbia University. 1190 Amsterdam Ave., New York, NY 10027, United States. E-mail: am4618@columbia.edu. Phone: 212-853-1406.

${ }^{c}$ Department of Psychology, Columbia University. 1190 Amsterdam Ave., New York, NY 10027, United States. E-mail: lah2201@columbia.edu. Phone: 212-854-1348. (Corresponding Author)

Wolle, R. G., McLaughlin, A., \& Heiphetz, L. (2021). The role of theory of mind and wishful thinking in children's moralizing concepts of the Abrahamic God. Journal of Cognition and Development, 22, 398-417. doi: 10.1080/15248372.2021.1888731 
MORALIZING GOD CONCEPTS

The authors thank Clara Apostolatos, Jenny Barshay, Grace Ding, Jared Fel, Devyani Goel, Lindsay Goolsby, Michael Herman, Brielle Internoscia, Rahil Kamath, Carolina SantiagoRobles, Simran Suresh, Aaliyah Triumph, and Haley Ward for assistance with data collection and coding; James Dunlea, Megan Goldring, and Ayse Payir for their feedback; and the Brooklyn Children's Museum, Traphagen Elementary School, and Crescent Elementary School for providing testing space. This project was made possible through the support of grant $\# 61080$ from the John Templeton Foundation to LH. The opinions expressed in this publication are those of the authors and do not necessarily reflect the views of the John Templeton Foundation. This work has also been supported (in part) by a Visiting Scholar award from the Russell Sage Foundation to LH. Any opinions expressed are those of the authors alone and should not be construed as representing the opinions of the Foundation. 
MORALIZING GOD CONCEPTS

\begin{abstract}
Adults conceptualize God as particularly knowledgeable — more knowledgeable than humans - about moral transgressions. We investigated how younger (4- to 5-year-old) and older (6- to 7-year-old) children view God's moral knowledge. Cultural narratives in the United States portray God as omniscient, which could lead children growing up in the United States to conclude that God knows their own and others' behaviors. However, older children are better able to distinguish between different minds, and this ability (theory of mind, or TOM) may predict a tendency for older, versus younger, children to attribute greater knowledge to God. Consistent with the latter possibility, 6- to 7-year-olds viewed God as more knowledgeable of their own and others' transgressions than did 4- to 5-year-olds. TOM partially mediated this difference. Further, children - particularly 4- to 5-year-olds - conceptualized God as more knowledgeable of others' transgressions than of their own. Study 2 probed whether 4- to 5- yearolds' responses were due to wishful thinking (e.g., they did not want God to know their transgressions and therefore reported that God would lack this knowledge). Supporting this prediction, 4- to 5-year-olds attributed greater knowledge to God of their own, versus others', pro-social acts. The extent to which children attributed knowledge of these acts to God predicted their own propensity to behave pro-socially by sharing with others. This work expands current understanding of religious cognition, particularly its connections with moral judgment and theory of mind.
\end{abstract}

Keywords: moral cognition; religious cognition; social cognitive development 
MORALIZING GOD CONCEPTS

\section{The Role of Theory of Mind and Wishful Thinking in Children's Moralizing Concepts of the Abrahamic God}

Learning to draw accurate inferences about others' minds is a core component of cognitive development. Understanding that another person feels sad, knows when someone is lying, or believes that others have malicious intentions can help people navigate increasingly complex social situations as they get older. To many adults, it may also seem obvious that the universe contains different kinds of minds. Two different people may have different amounts of knowledge regarding the social and natural universe, but simply by virtue of having a human mind, both people know more than an earthworm and less than God. Over the past several decades, psychologists have learned a great deal about how children come to distinguish different human minds from one another. However, children's reasoning about supernatural minds remains less well understood.

The current work examined how children reason about God's mind—an important case study because many people are explicitly taught that God's mind is quite different from human minds. In particular, traditional theology in Abrahamic faiths (i.e., Islam, Judaism, Christianity) portrays God's mind as omniscient and, therefore, unlike human minds (Barrett, 1999; Slone, 2004). Because the majority of United States residents affiliate with one of the Abrahamic faiths (Pew Research Center, 2015), predominant cultural narratives arising from these traditions also represent God's mind as distinct from human minds, although not all religions necessarily endorse this view. Children encounter these narratives in explicitly religious settings, such as places of worship. Even children from non-religious families can be exposed to such settings, as some parents who do not affiliate with a religion themselves nevertheless bring their children to religious services out of a sense that doing so may benefit their families (Ecklund \& Lee, 2011). 
MORALIZING GOD CONCEPTS

Children may also encounter representations of God in secular places; for instance, in public schools, they may observe classmates praying, notice that some peers are wearing religious clothing and jewelry, or discuss religious topics with other students (Pew Research Center, 2019; Tratner et al., 2017). Children are able to learn from others' testimony (Harris, Koenig, Corriveau, \& Jaswal, 2018), particularly when such testimony builds on capacities that children already possess and does not conflict with their first-hand observations (Lane \& Harris, 2014; Woolley \& Ghossainy, 2013). Consequently, children may conclude that God's mind differs from their own.

However, young children also experience difficulty distinguishing their own minds from those of other humans. For example, preschoolers typically report that other people know what they know (Wellman, Cross, \& Watson, 2001). These difficulties may lead children to conclude that all minds, including God's supernatural mind, are similar to theirs. Classic findings suggest that theory of mind (TOM) — the ability to accurately reason about others' mental states and distinguish one mind from another-emerges during the preschool years (Wellman et al., 2001). In one of the first studies demonstrating this effect (Wimmer \& Perner, 1983), children heard stories about characters who put an object in a particular location and then left the room. While the characters were gone, a different person moved the object. Children then indicated where these characters would look for the object when they returned. None of the 3- to 4-year-olds, approximately half of 4- to 6-year-olds, and the majority of 6- to 9-year-olds reliably reported that characters would look in the location where they had left the object despite the fact that children had seen the object move to a new location.

Indeed, Wimmer and Perner's (1983) work suggests that TOM abilities continue to develop even after the preschool years. More recent work supports this idea, showing 
MORALIZING GOD CONCEPTS

improvements in theory of mind after the age of four (Lane, Wellman, \& Evans, 2014; Wellman

$\&$ Liu, 2004). For example, the ability to succeed on second-order TOM tasks-which ask

participants to infer what one person believes about another person's knowledge—-typically

develops only after children have learned to pass first-order TOM tasks, which only ask them to

infer what one person believes about the state of the world (McGlamery, Ball, Henley, \&

Besozzi, 2007; Miller, 2009). Another task requiring TOM ability is understanding that the

emotions people display may differ from their actual emotions; in one previous line of work, less

than one-third of children between three and seven years old demonstrated this understanding

(Wellman \& Liu, 2004; see also Harris, Donnelly, Guz, \& Pitt-Watson, 1986).

Although a large body of work has investigated how children reason about human minds, children's reasoning about supernatural minds — which are often explicitly described as quite different from human minds (Barrett, 1999; Slone, 2004)—remains less clear. To the extent that past work has investigated children's judgments regarding God's mind, it has focused almost exclusively on God's knowledge of physical facts, such as where particular objects are located. By the age of five, children reliably attribute more knowledge of physical facts to God than to humans (Barrett, Newman, \& Richert, 2003; Barrett, Richert, \& Driesenga, 2001; Knight, 2008; Richert \& Barrett, 2005; Wigger, Paxson, \& Ryan, 2013). However, children younger than approximately five years of age sometimes attribute to God only knowledge that they themselves possess (Gimenez-Dasi, Guerrero, \& Harris, 2005; Kiessling \& Perner, 2014; Lane, Wellman, \& Evans, 2010; Makris \& Pnevmatikos, 2007). Further, preschoolers do not understand omniscience in the same way as older children and adults. For instance, in one line of work, 3- to 6.5-year-olds attributed less knowledge to an omniscient being (Ms. Smart, a being whom the experimenters described as knowing "everything about everything") than did 6.5- to 12-year-olds 
MORALIZING GOD CONCEPTS

and adults (Lane et al., 2014). In other words, preschoolers were more likely than elementary schoolers and adults to view the knowledge of an omniscient being as limited in a similar way as the knowledge of ordinary human beings is limited. Together, these studies suggest that reasoning about God's knowledge of facts may be linked with reasoning about humans' knowledge of facts, as children begin distinguishing God's mind from human minds around the same age that they begin to distinguish different human minds from one other.

Past work has not focused on how children might conceptualize God's knowledge in other domains, such as morality, although some developmental research has addressed related questions. As described above, one project asked how 3- to 12-year-olds attribute knowledge of diverse information, including knowledge regarding past behaviors, to a fictional person described as omniscient (Lane et al., 2014). Another series of studies showed that 5- to 8-yearolds attribute similar moral beliefs (e.g., that it is not okay to hit) to themselves, other humans, and God (Heiphetz, Lane, Waytz, \& Young, 2018). However, this work did not ask participants to attribute moral knowledge to God (e.g., whether God knows when people hit each other).

Children do link religious concepts with morality, attributing more moral behaviors to peers who share their religious beliefs than to religious out-group members (Heiphetz, Spelke, \& Banaji, 2014) and taking religious versus secular motivation into account when determining how good or bad a particular behavior is (Heiphetz, Spelke, \& Young, 2015). However, the bulk of the work examining moral attributions to God comes from the adult literature. Adults view God as a moralizing agent who knows and cares about moral transgressions (Norenzayan, 2013; Roes \& Raymond, 2003). Although they explicitly report that God knows everything, adults attribute to God greater knowledge of morally relevant than neutral information (Purzycki, 2013) and are faster to report that God knows about bad acts than good acts or morally neutral information 
MORALIZING GOD CONCEPTS

(Purzycki et al., 2012). Building on this research, the current work examined how children attribute knowledge of morally relevant behaviors to God. Furthermore, to examine possible selfother discrepancies, the current work asked children about God's knowledge regarding their own behaviors as well as those performed by other people.

\section{Study 1}

Study 1 tested two competing hypotheses. On the one hand, children can learn from others' testimony (Harris et al., 2018), and cultural narratives in the United States often portray God as omniscient (Barrett, 1999; Slone, 2004). Thus, children may attribute broad knowledge to God, including knowledge of both their own transgressions and others' transgressions. On the other hand, 4- to 5-year-olds have less well-developed TOM abilities compared with 6- to 7year-olds (e.g., Wimmer \& Perner, 1983) and may not understand that God can know moral information that they themselves do not know. Thus, older children may attribute greater knowledge to God than do younger children. Additionally, children know when they commit transgressions but do not necessarily know when others do so. Thus, younger children may attribute greater knowledge to God of their own transgressions (of which they would be aware when committing them) than of others' transgressions (of which children may lack awareness; for work showing that preschoolers can reason about hypothetical behaviors, see Atance \& O’Neill, 2005; Kuczaj \& Daly, 1979). In testing between these hypotheses, Study 1 clarified how children attribute knowledge to God regarding both their own behaviors and others' behaviors.

\section{Method}

Participants. Participants were 72 4- to 5-year-olds and 70 6- to 7-year-olds. The demographics for the 4- to 5-year-olds were as follows: $M_{\text {age }}=4.46$ years, $S D_{\text {age }}=.50$ years; $58 \%$ female; 35\% White or European-American, 28\% Black or African-American, $8 \%$ Asian or 
MORALIZING GOD CONCEPTS

Asian-American, 18\% multiracial, 6\% other, remainder unspecified; 19\% Hispanic or Latina/o

(families indicated ethnicity separately from race on our demographic questionnaire); 6\%

Protestant, 10\% Catholic, 26\% other Christian, 11\% Jewish, 3\% Muslim, 32\% non-

religious/atheist/agnostic (these options were grouped together on our demographic

questionnaire), $8 \%$ other, remainder unspecified. The demographics for the 6- to 7-year-olds

were as follows: $M_{\mathrm{age}}=6.37$ years, $S D_{\mathrm{age}}=.49$ years; $53 \%$ female; $33 \%$ White or European-

American, 14\% Black or African-American, 11\% Asian or Asian-American, 1\% Native

American/Pacific Islander, 23\% multiracial, 11\% other, remainder unspecified; 23\% Hispanic or

Latina/o; 1\% Protestant, 19\% Catholic, 24\% other Christian, 13\% Jewish, 3\% Buddhist, 1\%

Hindu, 20\% non-religious/atheist/agnostic; $11 \%$ other; remainder unspecified. ${ }^{1}$ Data from nine

additional children were excluded because the child did not understand the study $(n=1)$, because

the parent or sibling interfered during testing $(n=4)$, because the parent did not indicate the

child's age on the demographic questionnaire $(n=1)$, and because the child observed their sibling

complete the study immediately before participating, which may have influenced their own

responses $(n=3) .^{2}$ We recruited participants via a lab database and in collaboration with a

\footnotetext{
${ }^{1}$ Preliminary analyses compared members of different religious groups in two ways. First, we compared children whose parents reported raising them in any kind of religious background with children whose parents identified their affiliation as non-religious/atheist/agnostic. We made this comparison because children who are raised in a religious tradition may make different judgments about God's mind than children who are not raised in a religious tradition. Second, we compared children from Protestant, Catholic, and "other Christian" backgrounds with all other children. We made this comparison because Christianity is the dominant religious group in the United States, and members of the dominant group may differ from members of other groups. Here and in Study 2, religious background did not reliably predict children's attributions of knowledge to God. Further, our pre-registered analyses did not focus on religious background, as this was not the main variable of interest in these studies. Therefore, the results presented below collapse across this variable.

${ }^{2}$ Similar attributions of knowledge to God as those reported below emerged when including all respondents in analyses. The $95 \%$ confidence intervals for the indirect effects in the mediation models included zero when analyzing data from all respondents (attributions of knowledge
} 
MORALIZING GOD CONCEPTS

museum in the northeastern United States, and they received a small prize for participating (small toy for lab participants; sticker for museum participants).

Procedure. The procedure and analyses for Study 1 were pre-registered, and the preregistration is available at http://aspredicted.org/blind.php? $=46 \mathrm{mg} 5 \mathrm{~g}$. An experimenter tested each participant individually. After obtaining written consent from the parent or legal guardian and verbal assent from the child, the experimenter administered a battery of standard TOM tasks followed by items regarding conceptualizations of God's knowledge regarding the participants' own and others' transgressions. In line with recommendations for mediation designs, all TOM tasks (the hypothesized mediator) preceded all dependent measures (Baron \& Kenny, 1986). We administered the TOM tasks in the order outlined below, with easier tasks occurring prior to more cognitively taxing tasks, in order to avoid depleting participants at the beginning of the study. The order of questions about God's knowledge was counterbalanced across participants. While children completed the study, their parent or legal guardian completed a demographic questionnaire.

Participants first completed four frequently used TOM tasks that have been validated in prior research. To avoid ceiling effects, we selected tasks that vary in difficulty, such that even older children were expected to fail the more difficult tasks sometimes (Miller, 2009; Wellman \& Liu, 2004). The four tasks were as follows: (1) False Belief Task (Wimmer \& Perner, 1983), which tested whether participants understood that others could hold mistaken beliefs about the

regarding others' transgressions: 13 [-.05, .31]; attributions of knowledge regarding one's own transgressions: .19 [-.02, .42]). In Study 2, only one respondent was excluded, and the reason was that he/she was not in the age group targeted by this study. Therefore, we performed Study 2 analyses only on non-excluded participants. 
MORALIZING GOD CONCEPTS

location of an object; (2) Unexpected Contents Task (Gopnik \& Astington, 1988), which tested whether participants understood that others could hold mistaken beliefs about the contents of a container; (3) Real Apparent Emotion Task (Wellman \& Liu, 2004; adapted from Harris et al., 1986), which tested whether participants understood that people could conceal their true emotions; and (4) Second-Order TOM Task (McGlamery et al., 2007), which tested whether participants could attribute false beliefs to one person about the mental states of another person. For additional details about how we scored these tasks, see Supplemental Materials.

After completing all theory of mind tasks, participants attributed knowledge to God. In one block, they answered five questions about God's knowledge of their own transgressions (e.g., "Do you think God knows if you take something that belongs to a classmate without asking?"). It was rare for children to protest that they would never commit these transgressions, but three children did make comments along these lines. In these cases, the experimenter reiterated that he or she was interested in whether God would know if children committed a transgression. All children answered the questions when the experimenter highlighted this hypothetical. In another block, participants indicated whether they thought God would know if another person committed those same transgressions (e.g., "Do you think that God knows if [Lisa/Larry, matched to participant's gender] takes something that belongs to a classmate without asking?").

The experimenter prefaced both blocks by saying, "Now I'm going to ask you some questions about what you think God knows about [you/another person named Lisa/another person named Larry]. Remember, there are no right or wrong answers; I just want to know whatever you think.” Transgression items were drawn from prior work (Dunham, Baron, \& Carey, 2011; Heiphetz et al., 2015; Purzycki et al., 2012). In addition to the example above, the 
MORALIZING GOD CONCEPTS

other transgressions included saying something mean to a friend, telling a lie, being mean to someone at school, and pulling someone's hair (see Appendix). Participants first responded "yes," God would know about the transgression, or "no," God would not know about the transgression. They then indicated whether they were "really sure," "kind of sure," or "not very sure" of their response. Responses were coded using a scale from -2.5 to +2.5 . Because participants could not obtain a score of 0 , this coding allowed for the distance between scores on the same side of 0 (e.g., -2.5 , indicating that the participant was "very sure" regarding God's lack of knowledge, and -1.5, indicating that the participant was "kind of sure" regarding God's lack of knowledge) to correspond to the distance between scores on opposite sides of 0 (e.g., -0.5 , indicating that the participant was "not very sure" about God's lack of knowledge, and +0.5 , indicating that the participant was "not very sure" about the presence of God's knowledge). The order of blocks, and of questions within each block, was counterbalanced across participants.

\section{Results}

To examine attributions of knowledge to God, we conducted a 2 (Participant Age: younger vs. older) $\mathrm{x} 2$ (Target: self vs. other) mixed ANOVA with repeated measures on the second factor. ${ }^{3}$ This analysis revealed a main effect of Participant Age, $F(1,135)=35.74, p<.001$,

\footnotetext{
${ }^{3}$ Our pre-registration specified particular comparisons of theoretical interest rather than the omnibus ANOVA, and we report the results of these comparisons here. First, to test whether 6to 7-year-olds attributed to God a "high" level of knowledge about transgressions, we used a one-sample $t$-test to compare mean responses across the five "self" transgressions to zero (the scale's midpoint), $t(69)=7.42, p<.001$, Cohen's $d=.89$. We used a second one-sample $t$-test to perform the same analysis on mean responses across the five "other" transgressions, $t(69)=9.71$, $p<.001$, Cohen's $d=1.16$. The fact that both means were significantly above zero indicates that older children did, in fact, attribute "high" levels of moral knowledge to God. Second, we tested whether 4- to 5-year-olds attributed to God less knowledge of others' transgressions (a) than of their own transgressions and (b) than did 6- to 7-year-olds. To address the first of these possibilities, we conducted a paired-samples $t$-test comparing 4- to 5-year-olds' responses to the "self" transgressions versus the "other" transgressions. Although 4- to 5-year-olds did distinguish between their own and others' transgressions, the difference was in the opposite direction as
} 
MORALIZING GOD CONCEPTS

$\eta_{\mathrm{p}}{ }^{2}=.21$. Older children $(M=1.38, S D=1.26)$ reported more certainty than did younger children

$(M=.03, S D=1.35)$ that God knew of transgressions. The omnibus ANOVA also revealed a main

effect of Target, $F(1,135)=9.21, p=.003, \eta_{\mathrm{p}}^{2}=.06$. Participants reported more certainty that God

knew others' transgressions $(M=.86, S D=1.48)$ than their own $(M=.58, S D=1.67)$. The Participant

Age $\mathrm{x}$ Target interaction did not reach significance, $F(1,135)=2.44, p=.121, \eta_{\mathrm{p}}{ }^{2}=.02$. Figure 1

illustrates these effects. Although 95\% confidence intervals are often interpreted as indicating statistical significance, examining overlap between confidence intervals does not always lead to the same conclusion as performing a formal test of significance (e.g., Schenker \& Gentleman, 2001).

[Insert Figure 1 near here]

To investigate the link between attributions of knowledge to God and TOM, we calculated one TOM score for each participant. Scores represented a proportion in which the number of points participants earned for all the TOM tasks in which they passed the comprehension checks served as the numerator and the number of points possible for all the TOM tasks in which they passed the comprehension checks served as the denominator. Across all TOM tasks, the measures included six comprehension checks (see Supplementary Materials). When participants failed a comprehension check item, it was not clear how to interpret their responses to the main variables of interest (e.g., if a participant did not remember that someone had moved an object while the character in the story was out of the room, and then reported that

what we expected: they were more likely to attribute knowledge to God when responding about others' transgressions compared to their own $(t(66)=-3.05, p=.003$, Cohen's $d=-0.28)$. To address the second of these possibilities, we conducted an independent-samples $t$-test showing that 4 - to 5 -year-olds were less likely than 6- to 7-year-olds to attribute knowledge of others' transgressions to $\operatorname{God}(t(133)=-5.19, p<.001$, Cohen's $d=-.90)$. For completeness, we also investigated whether 4- to 5-year-olds were less likely to attribute knowledge regarding their own transgressions to God, and found that they were $(t(135)=-5.83, p<.001$, Cohen's $d=-1.00)$. 
MORALIZING GOD CONCEPTS

the character would look for that object in the place where he had left it, it is not clear whether this response indicates theory of mind capacity or the belief that the character would look in the place where the participant falsely believes the object to be located). Thus, we did not include their incorrect responses to the target question(s) in the analysis for that particular task. The rates of failing comprehension check items were as follows: $19 \%$ of participants failed the comprehension checks in the False Belief Task; $6 \%$ of participants failed the comprehension check in the Unexpected Content Task; and 50\% of participants failed the comprehension checks in the Second-Order TOM Task. ${ }^{4}$ For average TOM scores across age groups, see Supplementary Materials.

To test whether TOM could explain age-related differences, we examined whether TOM mediated the difference between younger and older children's attribution of knowledge to God regarding transgressions. ${ }^{5}$ To do so, we used PROCESS (Hayes, 2018) with 5,000 bootstrapped samples. Age group (younger versus older) was entered as the predictor variable, TOM as the mediator, and attributions of knowledge as the dependent variable. As shown in Figures 2-3,

\footnotetext{
${ }^{4}$ The Real Apparent Emotion Task did not include the same types of comprehension check questions as the other tasks. It did ask participants to recall components of the story, but the ability to demonstrate theory of mind on the main questions of interest did not depend on recalling those details (e.g., a child may understand that someone can display different emotions than the ones they truly feel without being able to readily recall why they want to do that). Therefore, our main analyses included responses to this task regardless of children's answers to the memory questions. Because this task was the only one that did not measure false beliefs and therefore had a different type of set-up from the other tasks, we also re-ran the mediation analyses using only the three false belief tasks and excluding the Real Apparent Emotion Task. These models showed a significant indirect effect when the dependent variable was God's knowledge of participants' own transgressions $(.22[.05, .44])$ and did not show a significant indirect effect when the dependent variable was God's knowledge of others' transgressions (.12 [$.03, .31])$.

${ }^{5}$ We pre-registered analysis for only the "other" mediation, but we present both here for completeness.
} 
MORALIZING GOD CONCEPTS

TOM partially mediated the relation between participant's age group and attributions of knowledge to God regarding both their own and others' transgressions.

[Insert Figure 2 near here]

[Insert Figure 3 near here]

\section{Discussion}

The main goal of Study 1 was to test between two hypotheses regarding children's attributions of moral knowledge to God. On the one hand, because cultural narratives in the United States portray God as all-knowing (Barrett, 1999; Slone, 2004), children growing up in this culture may report that God has broad knowledge, including knowledge of others' transgressions as well as the participants' own. On the other hand, because older children are better able to distinguish between their own minds and others' minds than are younger children, age-related differences based on TOM may emerge in attributions of knowledge to God.

Findings largely supported the second possibility. Older children readily attributed moral knowledge to God, more so than did younger children, and TOM abilities partially mediated this age difference. In other words, older children obtained higher scores than younger children on tasks measuring their ability to distinguish different agents' minds from each other, and performance on these tasks predicted the extent to which children attributed moral knowledge to God.

However, one unexpected finding emerged: participants attributed to God greater knowledge of others' transgressions than of their own. Neither of the alternative hypotheses we tested predicted this outcome. If children responded in line with cultural testimony, they should have attributed to God equally high knowledge of all transgressions; if they responded based on TOM abilities, they should have attributed to God more knowledge of their own transgressions, 
MORALIZING GOD CONCEPTS

with which they would be familiar if they performed them, than of others' transgressions. Study

2 tested a possible explanation for this result.

\section{Study 2}

The main purpose of Study 2 was to investigate why children might attribute to God greater knowledge of others' transgressions rather than their own. Although the omnibus ANOVA in Study 1 suggested that participants in general showed this pattern (e.g., we found a main effect of Target and did not observe a significant interaction with Participant Age), our preregistered pairwise comparisons indicated that this effect emerged particularly strongly among 4to 5-year-olds. Therefore, we only recruited 4- to 5-year-olds in Study 2.

One possibility is that young children engage in wishful thinking and therefore report that God is, to some extent, less likely to know about their own transgressions because they do not want God to know what they have done wrong. This account would explain why 4- to 5-yearolds may have attributed to God somewhat greater knowledge of others' transgressions than their own, as older children may be less prone to engage in wishful thinking (Bernard, Clement, \& Mercier, 2016; Wente et al., in press). To test whether wishful thinking may have driven younger children's responses in Study 1, we asked 4- to 5-year-olds about God's knowledge of their own and others' pro-social behaviors in addition to transgressions. If children in this age group are reporting what they want to be true, they may be more likely to report that God knows about their own, compared to others', pro-social behaviors.

A second goal of Study 2 was to examine links between attributions of moral knowledge to God and participants' own behaviors. The more moral knowledge participants attribute to God, the more likely they may be to perform pro-social actions. In other words, children who are certain that God knows their actions may perform more of the kinds of behaviors that God 
MORALIZING GOD CONCEPTS

ostensibly prefers. Because United States culture typically portrays God as wanting people to perform pro-social behaviors (Evans, 2013; Hare, 2007; Heiphetz et al., 2018), attributing greater moral knowledge to God may predict greater pro-sociality.

\section{Method}

Participants. We recruited participants in partnership with two local elementary schools and a museum as well as via a lab database. Due to the schools' request, participants recruited there did not receive a prize; other participants received a small toy (in lab) or sticker (at the museum). All participants resided in the northeastern United States. We tested 55 4- to 5-yearolds $\left(M_{\text {age }}=4.45\right.$ years, $S D_{\text {age }}=.50$ years; $36 \%$ female; $62 \%$ White or European-American, $9 \%$ Black or African-American, 15\% Asian or Asian-American, 11\% multiracial, 2\% other, remainder unspecified; $16 \%$ Hispanic or Latina/o; 5\% Protestant, 36\% Catholic, 16\% other Christian, 2\% Muslim, 4\% Buddhist, 29\% non-religious/atheist/agnostic, 7\% other, remainder unspecified). Data from one additional respondent were excluded because the child aged out of the study before the interview was conducted.

Procedure. The procedure and analyses for Study 2 were pre-registered, and the preregistration is available at http://aspredicted.org/blind.php? $\mathrm{x}=\mathrm{he} 34 \mathrm{vt}$. The procedure was identical to Study 1, with three exceptions. First, participants in Study 2 did not complete any TOM tasks. Second, in addition to answering questions about their own and others' transgressions, participants answered questions about their own and others' pro-social actions (e.g., whether God would know if they/another person helped someone; for all items, see Appendix). Questions about transgressions and pro-social items appeared in an interleaved fashion in each block (e.g., in one version, participants might answer one question about a prosocial action, two questions about transgressions, another question about a pro-social action, 
MORALIZING GOD CONCEPTS

etc.). Third, after answering all questions about God's knowledge, participants received five stickers. After giving the participant the stickers, the experimenter said, "So now we're going to play a sticker game. You can decide how many stickers you want to give a kid you have never met who will play this game at a different place later. You can give as many stickers as you want, but you cannot keep any for yourself. Any stickers you want to give to the next kid can go in this envelope. Any stickers that you do not want to give to this person can go in the trash envelope here, and I will throw them away when we finish. Does that make sense? So, remember, any stickers you want to give will go in here [pointing to the first envelope] and any stickers you don't want to give will go in here [pointing to the second envelope]. Okay, I'm going to turn around now, and you can decide what you want to do with the stickers. When you've made up your mind, just say 'done.'” Participants then distributed the stickers as they saw fit.

Study 2 contained three blocks. In one block, participants answered questions about God's knowledge of their own transgressions and pro-social actions. In another block, participants answered questions about God's knowledge of others' transgressions and pro-social actions. The order of the two blocks, and questions within each block, was counterbalanced across participants. In a third and final block, participants completed a sharing task. The sticker sharing task always appeared last and was not counterbalanced.

\section{Results}

To examine attributions of knowledge to God, we conducted a 2 (Target: self vs. other) x 2 (Act: pro-social vs. transgression) within-subjects ANOVA (Figure 4). The main effect of Target did not reach significance, $F(1,54)=.09, p=.776, \eta_{\mathrm{p}}{ }^{2}=.002$. However, the ANOVA revealed a main effect of Act, $F(1,54)=70.08, p<.001, \eta_{\mathrm{p}}{ }^{2}=.57$ : participants reported stronger 
MORALIZING GOD CONCEPTS

certainty that God knew their own and others' pro-social actions $(M=1.24, S D=0.89)$ versus transgressions $(M=-.14, S D=0.95)$.

The omnibus ANOVA also revealed a Target $\mathrm{x}$ Act interaction, $F(1,54)=15.33, p<.001$, $\eta_{\mathrm{p}}{ }^{2}=.22$. To investigate this interaction, we conducted two types of pairwise comparisons. First, and of most relevance to our hypothesis regarding wishful thinking, we compared how participants attributed knowledge of their own versus another person's pro-social acts and, separately, their own versus another person's transgressions. This analysis included two comparisons; therefore, the significance threshold was $p=.025$ after a Bonferroni correction. Replicating Study 1, participants attributed to God greater knowledge of another person's, versus their own, transgressions ( $p=.009$, Cohen's $d=-.36$ ). In contrast, and in line with the possibility that participants were engaging in wishful thinking, they attributed to God greater knowledge of their own, versus another person's, pro-social acts ( $p=.002$, Cohen's $d=.44)$. Second, we compared how participants attributed knowledge of pro-social versus anti-social acts performed by themselves and, separately, another person. This analysis included two comparisons; therefore, the significance threshold was $p=.025$ after a Bonferroni correction. Participants reported that God would have greater knowledge of pro-social acts, versus transgressions, performed by both themselves ( $p<.001$, Cohen's $d=1.36)$ and another person ( $p=.001$, Cohen's $d$ $=.50)$.

\section{[Insert Figure 4 near here]}

To determine whether attributions of knowledge to God were associated with children's own pro-social actions, we correlated attributions of knowledge regarding pro-social actions and transgressions with the number of stickers children shared with others. This analysis included two comparisons; therefore, $p$ values needed to be .025 or lower to pass the Bonferroni-corrected 
MORALIZING GOD CONCEPTS

significance threshold. The more knowledge of pro-social actions children attributed to God, the more stickers they shared with others $(r=.41, p=.002)$. The association between attributions of knowledge regarding transgressions and children's generosity did not reach significance ( $r=.06$, $p=.670)$.

\section{Discussion}

The main goal of Study 2 was to investigate why participants in Study 1 may have attributed to God greater knowledge of others' transgressions rather than their own. Study 2 tested whether this result could have occurred due to children's wishful thinking. Four- to fiveyear-olds may have wanted to believe that God would lack knowledge of their own transgressions and therefore reported that God actually lacked such knowledge. Study 2 supported this prediction by showing that children in this age group attributed greater knowledge of their own, versus others', pro-social acts to God. This effect occurred despite the fact that Study 2 replicated the result from Study 1 showing that 4- to 5-year-olds attribute greater knowledge of others', versus their own, transgressions to God. Taken together, these results suggest that preschoolers do not merely attribute to God greater knowledge of acts performed by either themselves or others. Rather, children's attributions appear sensitive to the valence of the behavior.

A second goal of Study 2 was to investigate potential links between attributions of moral knowledge to God and participants' own actions. Here, we reasoned that children who exhibit more certainty that God knows about pro-social acts may be more likely to perform such acts themselves. Cultural narratives in the United States often portray God as wanting people to behave pro-socially, and children as well as adults largely endorse such narratives (Evans, 2013; Hare, 2007; Heiphetz et al., 2018). Therefore, greater certainty that God knows when people 
MORALIZING GOD CONCEPTS

engage in pro-social acts may be associated with a stronger propensity to perform those acts, which God presumably values. Study 2 supported this prediction by showing that the more participants attributed knowledge to God regarding pro-social acts, the more stickers they shared with another person.

\section{General Discussion}

\section{Attributions of Moral Knowledge to God}

The current work examined how children attribute knowledge of morally relevant behaviors to God. We began with two competing hypotheses. On the one hand, cultural narratives often portray God as all-knowing (Barrett, 1999; Slone, 2004), and young children sometimes endorse testimony they hear from others (Harris et al., 2018). Therefore, children of all ages tested here may attribute high levels of knowledge regarding all types of morally relevant behaviors to God. On the other hand, young children possess less sophisticated skills than do older children in theory of mind, or TOM — the ability to reason about others' mental states and distinguish others' minds from their own (Wellman et al., 2001; Wimmer \& Perner, 1983). Although classic studies addressing TOM have focused on children's abilities to understand the existence of others' false beliefs, more recent work suggests that TOM also mediates the ability to attribute knowledge that children themselves lack to supernatural agents (Lane et al., 2010). In other words, children who do not yet reliably pass TOM tasks are less likely than children who do pass such tasks to report that others may have information that the children themselves lack. Thus, younger children may infer that God's mind is relatively similar to their own human mind and that God would only know about morally relevant behaviors with which children themselves would be familiar. Under this hypothesis, 6- to 7-year-olds (who have better-developed TOM abilities) would be more likely to attribute knowledge to God than would 
MORALIZING GOD CONCEPTS

4- to 5-year-olds (whose TOM abilities are still emerging). Supporting this second hypothesis,

Study 1 showed that 6- to 7-year-olds attributed to God greater knowledge of transgressions than did 4- to 5-year-olds. TOM partially mediated this difference, suggesting that older children attributed greater knowledge to God because they were better able to distinguish God's allknowing mind from humans' more limited minds than were younger children.

Study 2 followed up on a surprising result from Study 1 showing that children (4- to 5year-olds in particular) attributed to God somewhat greater knowledge of others', rather than their own, transgressions. We reasoned that this result may have occurred due to wishful thinking. In other words, participants may have attributed somewhat less knowledge to God of their own, versus others', transgressions because they did not want God to know about their own wrongdoings. Study 2 supported this hypothesis by (a) replicating the result that 4- to 5-year-olds attribute to God greater knowledge of others', versus their own, transgressions and (b) showing an opposite result for pro-social acts, with 4- to 5-year-olds attributing to God greater knowledge of their own, versus others', good deeds.

Taken together, these findings extend work on children's God concepts. Prior research in this area has focused on how children attribute knowledge of physical facts to God (for a review, see Heiphetz, Lane, Waytz, \& Young, 2016; for exceptions, see Heiphetz et al., 2018; Lane et al., 2014). This prior work indicates that judgments regarding God's supernatural mind are intertwined with judgments regarding humans' ordinary minds, as changes in attributions of factual knowledge to God occur around the same age as changes in TOM. However, this has been established almost exclusively regarding factual knowledge, with tasks similar to those used to measure TOM. For instance, children's ability to distinguish their own mind from the minds of other humans (by reporting that other humans will not know the contents of a box that 
MORALIZING GOD CONCEPTS

the child participant has seen but the other person has not seen) is associated with children's ability to distinguish human minds from God's mind (by reporting that God will know the contents of a box despite not having visual access to it; Lane et al., 2010). The current work extended this past research by showing that TOM measures such as those used in previous studies predict a very different type of outcome - attributing knowledge of morally relevant actions, which was not a feature of any of the TOM tasks, to God.

The current findings also extend prior work on adults' religious and moral cognition. Although adults report that God is omniscient, they attribute greater knowledge to God of transgressions than of pro-social or neutral behaviors on implicit tasks (Purzycki et al., 2012). In many domains, including religion, adults' implicit responses track children's explicit responses. For example, adults explicitly report that God is quite different from a person but implicitly view God as person-like. Adults' implicit views align with children's explicit responses, which often portray God as more person-like than do adults' explicit responses (Heiphetz et al., 2016). From this perspective, it is surprising that children in Study 2 attributed to God greater knowledge of pro-social acts than of transgressions, since previous work has suggested that adults implicitly view God as more knowledgeable about morally blameworthy than morally praiseworthy acts (Purzycki et al., 2012). This result may have emerged because children are generally optimistic about others; they selectively attend to information that portrays others in a positive light (Boseovski, 2010) and view moral goodness as more innate and less changeable than moral badness (Heiphetz, 2019). By investigating children's responses concerning conceptual questions that have previously been the focus of adult work (e.g., regarding the extent of God's knowledge about morally relevant acts), the present work is well positioned to create a bridge between developmental psychology and areas of study that focus on adults, such as social and cognitive 
MORALIZING GOD CONCEPTS

psychology. In so doing, the current work unites research on religious cognition with investigations of other aspects of social cognitive development, such as optimism.

\section{Relation between Religious Cognition and Behavior}

As discussed above, the primary goal of Study 2 was to investigate why children attribute to God different amounts of knowledge of their own versus others' morally relevant behaviors. A second goal was to determine the extent to which attributions of knowledge to God are associated with children's own behaviors. In past work, individuals have conceptualized God as an agent who cares that people behave pro-socially (Norenzayan, 2013; Roes \& Raymond, 2003). Attributing greater knowledge to God of pro-social actions may therefore predict the extent to which children perform such actions. In other words, believing that God knows when pro-social actions occur and that God wants such actions to occur may be associated with an increased likelihood of actually performing such actions. Study 2 supported this prediction by showing that the more children attributed knowledge of pro-social acts to God, the more stickers they shared with an anonymous peer.

This focus on behavior is an important contribution to work in the cognitive science of religion, which has largely emphasized cognition and attitudes. For instance, researchers have probed the extent to which children and adults endorse the existence of supernatural phenomena (Bering, Blasi, \& Bjorklund, 2005; Davoodi et al., 2019), the types of properties that people attribute to God and other supernatural beings (Heiphetz et al., 2018; Shtulman, 2008), and the degree to which individuals prefer people who share their views of God (Heiphetz et al., 2015; Johnson, Rowatt, \& LaBouff, 2012). These are all important questions, and answering them has done much to shape scientific understanding of religious cognition. At the same time, little is known about how such cognition might be associated with pro-social behavior, particularly 
MORALIZING GOD CONCEPTS

among children (for an exception focusing on adults, see Shariff, Willard, Andersen, \&

Norenzayan, 2016). The current work began to answer this question by showing that attributing greater knowledge of pro-social acts to God predicts children's propensity to perform a particular pro-social act (sharing stickers) themselves. This behavior did not appear associated with attributing greater knowledge of transgressions, a result that future research can probe further.

\section{Limitations and Future Directions}

The section above noted that attributions of knowledge to God regarding pro-social acts, but not of transgressions, predicted the extent to which children shared with others. Perhaps a link between attributions of knowledge regarding transgressions and children's sharing behavior did not emerge because the behavior we tested was itself a pro-social act. Although failing to share could be considered a transgression, this interpretation may not have been salient to participants; pro-social acts are often considered supererogatory, and individuals do not always conceptualize the failure to perform these acts as a moral violation (Kahn, 1992). Future work could determine whether attributing greater knowledge of transgressions to God predicts the extent to which children refrain from transgressing, either by testing behaviors that are routinely viewed as transgressions (e.g., giving children the opportunity to cheat and seeing whether they are more likely to refrain if they attribute greater knowledge of transgressions to God) or by making a "transgression" interpretation more salient in our sticker-sharing task (e.g., telling children that failing to share is wrong). Of course, it is also possible that children's behaviors are sensitive to attributions of knowledge regarding transgressions to God and that the task used here simply failed to capture this effect. In the absence of additional data, the present null effect should be interpreted with caution. 
MORALIZING GOD CONCEPTS

Future work can also further probe the role of religious testimony in children's emerging understanding of God. The current work did not find strong differences based on participants' religious background. However, all participants lived in the United States, which is a relatively religious country. It is possible that this broader cultural context shapes children's religious understanding more strongly than the more limited religious context of their family. For instance, even children from non-religious families in the United States are familiar with the concept of God, perhaps because they have learned some religious ideas outside their family (e.g., from friends, classmates, and the media). In a less religious country, children may be less likely to attribute any mental states to God, and any religious concepts that children do have may not be associated with their actions.

The results from the present study suggest that the testimony children receive regarding God's omniscience may differ to some extent from the ways in which their developing TOM allows them to represent God's mind. However, it is possible that testimony and cognitive development could reinforce each other in some circumstances. For instance, among older children and adults, narratives portraying God as omniscient could be particularly compelling because they complement these individuals' understanding that others' minds differ from their own (Lane \& Harris, 2014). Additionally, although the current work provided evidence that TOM may underlie some age-related differences in attributions of some types of knowledge to God, we did not show that this is the only possible mechanism. Indeed, many social and cognitive processes change during the preschool and early elementary school years, and multiple factors could underlie the changes observed here. Future work can further probe the links between testimony and TOM and investigate other potential mechanisms underlying the agerelated changes observed here. 
MORALIZING GOD CONCEPTS

At a broader level, future work can investigate the extent to which the findings reported here generalize beyond God concepts. Children in preschool and early elementary school sometimes distinguish God from other agents. For instance, they attribute different types of factual knowledge to God versus their mother, an animal, or an imaginary friend (Barrett et al., 2001; Wigger et al., 2013). It is possible that children also attribute moral knowledge to God in a special way. An alternative possibility is that the effect shown here generalizes to beings that are particularly associated with morality. Even if children would attribute greater moral knowledge to God than to a person or animal, they may draw fewer distinctions between God and an agent like Santa, who is explicitly described as knowing when children are "good" or "bad." Scholars have argued that God concepts differ from Santa on a conceptual level (Barrett, 2008) and shown that adults distinguish between these two agents (Purzycki et al., 2012). Future work can determine how these views develop.

\section{Conclusions}

The current work investigated children's attribution of moral knowledge to God as well as the link between such attributions and children's own pro-social acts. In Study 1, 6- to 7-yearolds attributed greater moral knowledge to God than did 4- to 5-year-olds, an effect partially mediated by performance on theory of mind tasks. An unexpected finding also emerged: children (particularly 4- to 5-year-olds) attributed to God greater knowledge of others', versus their own, transgressions. Study 2 showed that this effect may have been the result of wishful thinking and further indicated that the extent to which 4- to 5-year-olds attributed knowledge of pro-social acts to God predicted their own propensity to share with others. Taken together, these findings indicate that psychological processes that do not appear religious on their face, such as theory of mind and wishful thinking, can shape children's religious cognition. Such cognition, in turn, 
MORALIZING GOD CONCEPTS

predicts children's likelihood of engaging in pro-social acts. Despite theological narratives

portraying God as different from people, children's religious cognition appears intertwined with their understanding of — and interactions with — their fellow humans. 
MORALIZING GOD CONCEPTS

\section{References}

Atance, C. M., \& O’Neill, D. K. (2005). Preschoolers' talk about future situations. First Language, 25, 5-18. doi: 10.1177/0142723705045678

Baron, R. M., \& Kenny, D. A. (1986). The moderator mediator variable distinction in social psychological research: Conceptual, strategic, and statistical considerations. Journal of Personality and Social Psychology, 51, 1173-1182. doi: 10.1037/0022-3514.51.6.1173

Barrett, J. L. (1999). Theological correctness: Cognitive constraint and the study of religion. Method and Theory in the Study of Religion, 11, 325-339. doi:

$10.1163 / 157006899 X 00078$

Barrett, J. L. (2008). Why Santa Claus is not a god. Journal of Cognition and Culture, 8, 149161. doi: 10.1164/156770908X289251

Barrett, J., Newman, R. M., \& Richert, R. (2003). When seeing is not believing: Children's understanding of humans' and non-humans' use of background knowledge in interpreting visual displays. Journal of Cognition and Culture, 3, 91-108. doi:

$10.1163 / 156853703321598590$

Barrett, J. L., Richert, R. A., \& Driesenga, A. (2001). God's beliefs versus mother's: The development of nonhuman agent concepts. Child Development, 72, 50-65. doi: $10.1111 / 1467-8624.00265$

Bering, J. M., Blasi, C. H., \& Bjorklund, D. F. (2005). The development of 'afterlife' beliefs in religiously and secularly schooled children. British Journal of Developmental Psychology, 23, 587-607. doi: 10.1348/026151005X36498

Bernard, S., Clément, F., \& Mercier, H. (2016). Wishful thinking in preschoolers. Journal of Experimental Child Psychology, 141, 267-274. doi: 10.1016/j.jecp.2015.07.018 
MORALIZING GOD CONCEPTS

Boseovski, J. J. (2010). Evidence for "rose-colored glasses": An examination of the positivity bias in young children's personality judgments. Child Development Perspectives, 4, 212218. doi: 10.1111/j.1750-8606.2010.00149.x

Davoodi, T., Jamshidi-Sianaki, M., Abedi, F., Payir, A., Cui, Y. K., Harris, P. L., \& Corriveau, K. H. (2019). Beliefs about religious and scientific entities among parents and children in Iran. Social Psychological and Personality Science, 10, 847-855. doi: $10.1177 / 1948550618806057$

Dunham, Y., Baron, A. S., \& Carey, S. (2011). Consequences of “minimal” group affiliations in children. Child Development, 82, 793-811. doi: 10.1111/j.1467-8624.2011.01577.x

Ecklund, E. H., \& Lee, K. S. (2011). Atheists and agnostics negotiate religion and family. Journal for the Scientific Study of Religion, 50, 728-743. doi: 10.1111/j.14685906.2011.01604.x

Evans, C. S. (2013). God and moral obligation. Oxford, UK: Oxford University Press.

Giménez-Dasí, M., Guerrero, S., \& Harris, P. L. (2005). Intimations of immortality and omniscience in early childhood. European Journal of Developmental Psychology, 2, 285297. doi: $10.1080 / 17405620544000039$

Gopnik, A., \& Astington, J. W. (1988). Children's understanding of representational change and its relation to the understanding of false belief and the appearance-reality distinction. Child Development, 59, 26-37. doi: 10.2307/1130386

Hare, J. E. (2007). God and morality: A philosophical history. Malden, MA: Wiley-Blackwell. Harris, P. L., Donnelly, K., Guz, G. R., \& Pitt-Watson, R. (1986). Children's understanding of the distinction between real and apparent emotion. Child Development, 57, 895-909. doi: $10.2307 / 1130366$ 
MORALIZING GOD CONCEPTS

Harris, P. L., Koenig, M. A., Corriveau, K. H., \& Jaswal, V. K. (2018). Cognitive foundations of learning from testimony. Annual Review of Psychology, 69, 251-273. doi:

10.1146/annurev-psych-122216-011710

Hayes, A. F. (2018). Introduction to mediation, moderation, and conditional process analysis: A regression-based approach. New York, NY: Guilford Press.

Heiphetz, L. (2019). Moral essentialism and generosity among children and adults. Journal of Experimental Psychology: General, 148, 2077-2090. doi: 10.1037/xge0000587

Heiphetz, L., Lane, J. D., Waytz, A., \& Young, L. L. (2016). How children and adults represent God's mind. Cognitive Science, 40, 121-144. doi: 10.1111/cogs.12232

Heiphetz, L., Lane, J. D., Waytz, A., \& Young, L. L. (2018). My mind, your mind, and God's mind: How children and adults conceive of different agents' moral beliefs. British Journal of Developmental Psychology, 36, 467-481. doi: 10.1111/bjdp.12231

Heiphetz, L., Spelke, E. S., \& Banaji, M. R. (2014). The formation of belief-based social preferences. Social Cognition, 32, 22-47. doi: 10.1521/soco.2014.32.1.22

Heiphetz, L., Spelke, E. S., \& Young, L. L. (2015). In the name of God: How children and adults judge agents who act for religious versus secular reasons. Cognition, 144, 134-149. doi: 10.1016/j.cognition.2015.07.017

Johnson, M. K., Rowatt, W. C., \& LaBouff, J. P. (2012). Religiosity and prejudice revisited: Ingroup favoritism, out-group derogation, or both? Psychology of Religion and Spirituality, 4, 154-168. doi: 10.1037/a0025107

Kahn, P. H. (1992). Children's obligatory and discretionary moral judgments. Child Development, 63, 416-430. doi: 10.2307/1131489 
MORALIZING GOD CONCEPTS

Kiessling, F., \& Perner, J. (2014). God-mother-baby: What children think they know. Child Development, 85, 1601-1616. doi: 10.1111/cdev.12210

Knight, N. (2008). Yukatek Maya children's attributions of belief to natural and non-natural entities. Journal of Cognition and Culture, 8, 235-243. doi: 10.1163/156853708x358164

Kuczaj, S., \& Daly, M. J. (1979). The development of hypothetical reference in the speech of young children. Journal of Child Language, 6, 563-597. doi:

$10.1017 / \mathrm{S} 0305000900002543$

Lane, J. D., \& Harris, P. L. (2014). Confronting, representing, and believing counterintuitive concepts: Navigating the natural and the supernatural. Perspectives on Psychological Science, 9, 144-160. doi: 10.1177/1745691613518078

Lane, J. D., Wellman, H. M., \& Evans, E. M. (2010). Children's understanding of ordinary and extraordinary minds. Child Development, 81, 1475-1489. doi: 10.1111/j.14678624.2010.01486.x

Lane, J. D., Wellman, H. M., \& Evans, E. M. (2014). Approaching an understanding of omniscience from the preschool years to early adulthood. Developmental Psychology, 50, 2380-2392. doi: 10.1037/a0037715

Makris, N., \& Pnevmatikos, D. (2007). Children's understanding of human and super-natural minds. Cognitive Development, 22, 365-375. doi: 10.1016/j.cogdev.2006.12.003

McGlamery, M. E., Ball, S. E., Henley, T. B., \& Besozzi, M. (2007). Theory of mind, attention, and executive function in kindergarten boys. Emotional and Behavioural Difficulties, 12, 29-47. doi: 10.1080/13632750601135899

Miller, S. A. (2009). Children's understanding of second-order mental states. Psychological Bulletin, 135, 749-773. doi: 10.1037/a0016854 
MORALIZING GOD CONCEPTS

Schenker, N., \& Gentleman, J. R. (2001). On judging the significance of differences by examining the overlap between confidence intervals. The American Statistician, 55, 182186, doi: $\underline{10.1198 / 000313001317097960}$

Norenzayan, A. (2013). Big gods: How religion transformed cooperation and conflict. Princeton, NJ: Princeton University Press.

Pew Research Center. (2015). Religious landscape study. Retrieved on July $2^{\text {nd }}, 2020$, from https://www.pewforum.org/religious-landscape-study/.

Pew Research Center. (2019). For a lot of American teens, religion is a regular part of the public school day. Retrieved on August $17^{\text {th }}, 2020$, from https://www.pewforum.org/2019/10/03/for-a-lot-of-american-teens-religion-is-a-regularpart-of-the-public-school-day/.

Purzycki, B. G. (2013). The minds of gods: A comparative study of supernatural agency. Cognition, 129, 163-179. doi: 10.1016/j.cognition.2013.06.010

Purzycki, B. G., Finkel, D. N., Shaver, J., Wales, N., Cohen, A. B., \& Sosis, R. (2012). What does God know? Supernatural agents' access to socially strategic and non-strategic information. Cognitive Science, 36, 846-869. doi: 10.1111/j.1551-6709.2012.01242.x

Richert, R. A., \& Barrett, J. L. (2005). Do you see what I see? Young children's assumptions about God's perceptual abilities. International Journal for the Psychology of Religion, 15, 283-295. doi: 10.1207/s15327582ijpr1504_2

Roes, F., \& Raymond, M. (2003). Belief in moralizing gods. Evolution and Human Behavior, 24, 126-135. doi:10.1016/s1090-5138(02)00134-4

Shariff, A. F., Willard, A. K., Andersen, T., \& Norenzayan, A. (2016). Religious priming: A meta-analysis with a focus on prosociality. Personality and Social Psychology Review, 
MORALIZING GOD CONCEPTS

$$
\text { 20, 27-48. doi: 10.1177/1088868314568811 }
$$

Shtulman, A. (2008). Variation in the anthropomorphization of supernatural beings and its implications for cognitive theories of religion. Journal of Experimental Psychology: Learning, Memory, and Cognition, 34, 1123-1138. doi: 10.1037/0278-7393.34.5.1123

Slone, D. J. (2004). Theological incorrectness: Why religious people believe what they shouldn't. New York, NY: Oxford University Press.

Tratner, A. E., Sela, Y., Lopes, G. S., Ehrke, A. D., Weekes-Shackelford, V. A., \& Shackelford, T. K. (2017). Individual differences in childhood religious experiences with peers. Personality and Individual Differences, 119, 73-77. doi: 10.1016/j.paid.2017.06.045

Wellman, H. M., Cross, D., \& Watson, J. (2001). Meta-analysis of theory-of-mind development: The truth about false belief. Child Development, 72, 655-684. doi:10.1111/14678624.00304

Wellman, H. M., \& Liu, D. (2004). Scaling of theory-of-mind tasks. Child Development, 75, 523-541. doi: 10.1111/j.1467-8624.2004.00691.x

Wente, A. O., Goddu, M. K. Garcia, T., Posner, E., Flecha, M. F., \& Gopnik, A. (In press). Young children are wishful thinkers: The development of wishful thinking in 3- to 10year-old children. Child Development.

Wigger, J. B., Paxson, K., \& Ryan, L. (2013). What do invisible friends know? Imaginary companions, God, and theory of mind. International Journal for the Psychology of Religion, 23, 2-14. doi: 10.1080/10508619.2013.739059

Wimmer, H., \& Perner, J. (1983). Beliefs about beliefs: Representation and constraining function of wrong beliefs in young children's understanding of deception. Cognition, 13, 103-128. doi: 10.1016/0010-0277(83)90004-5 
MORALIZING GOD CONCEPTS

Woolley, J. D., \& Ghossainy, M. (2013). Revising the fantasy-reality distinction: Children as naive skeptics. Child Development, 84, 1496-1510. doi: 10.1111/cdev.12081 
MORALIZING GOD CONCEPTS

\section{Appendix}

Participants were instructed to reply "yes" or "no" to each item below. The experimenter then asked, "Are you really sure, kind of sure, or not very sure about that?" In the "self" condition, the agent was "you" (e.g., "Do you think God knows if you say something mean to your friend?"). In the "other" condition, the agent was gender-matched to the participant (e.g., "Do you think that God knows if [Lisa/Larry] says something mean to [her/his] friend?").

\section{Transgressions (Studies 1-2):}

Do you think God knows if [agent] says something mean to [agent's] friend?

Do you think God knows if [agent] tells [agent's] mom a lie?

Do you think God knows if [agent] takes something that belongs to a classmate without asking?

Do you think God knows if [agent] is mean to someone in [agent's] class at school?

Study 1: Do you think God knows if [agent] pulls someone's hair?

Study 2: Do you think God knows if [agent] pushes someone and they fall down?

Note: The final item was replaced in Study 2 to allow for a parallel pro-social behavior in that study (e.g., helping someone who fell down).

\section{Pro-Social Behaviors (Study 2):}

Do you think God knows if [agent] says something nice to [agent's] friend?

Do you think God knows if [agent] tells [agent's] mom the truth?

Do you think God knows if [agent] shares with a classmate?

Do you think God knows if [agent] is nice to someone in [agent's] class at school?

Do you think God knows if [agent] helps someone when they fall down? 
MORALIZING GOD CONCEPTS

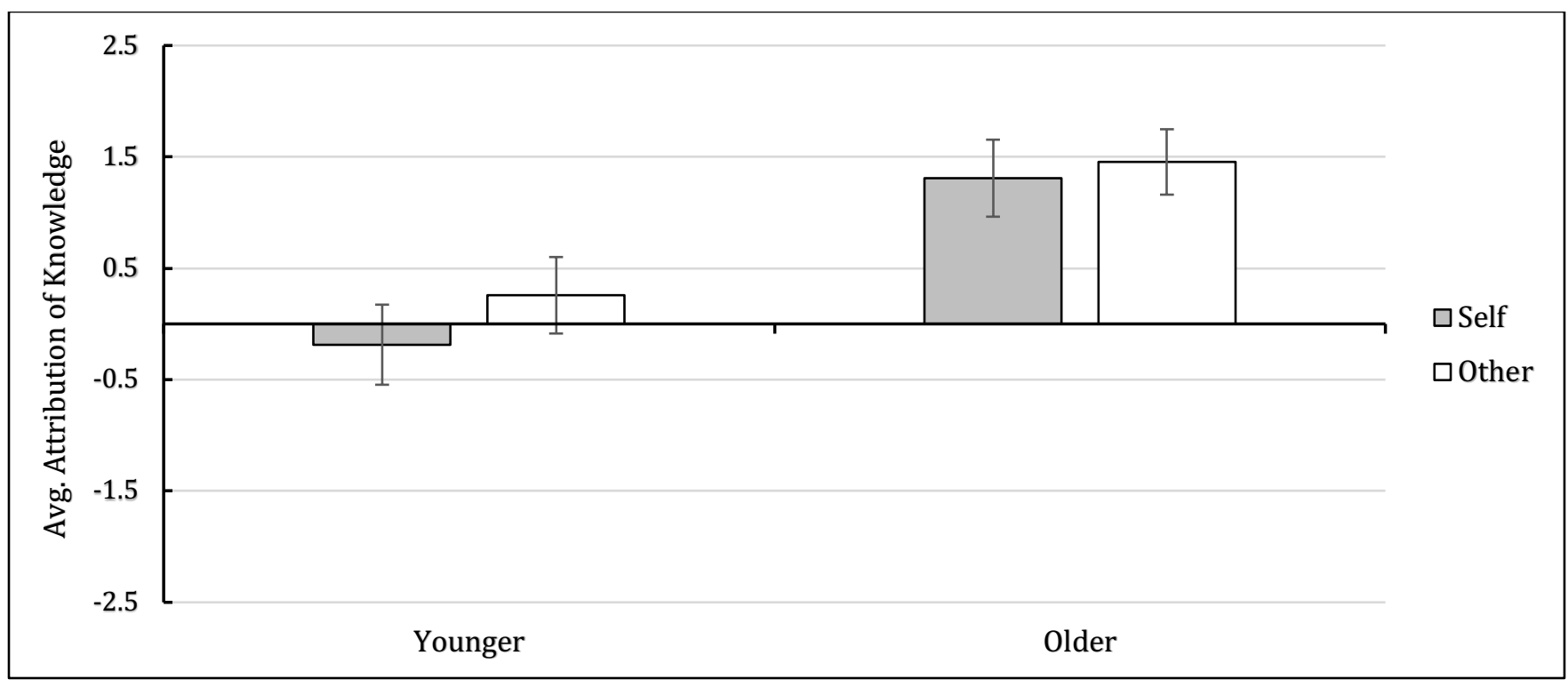

Figure 1. 


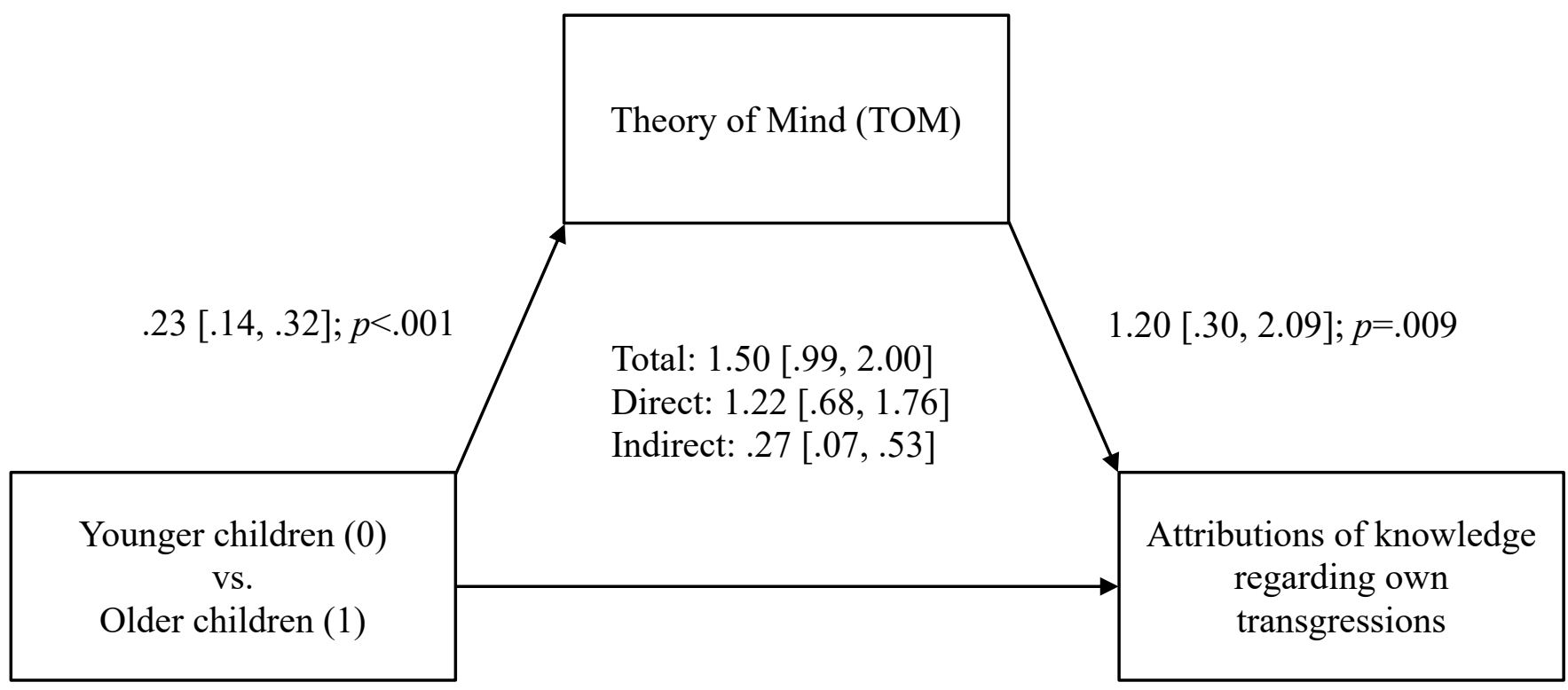

Figure 2. 
MORALIZING GOD CONCEPTS

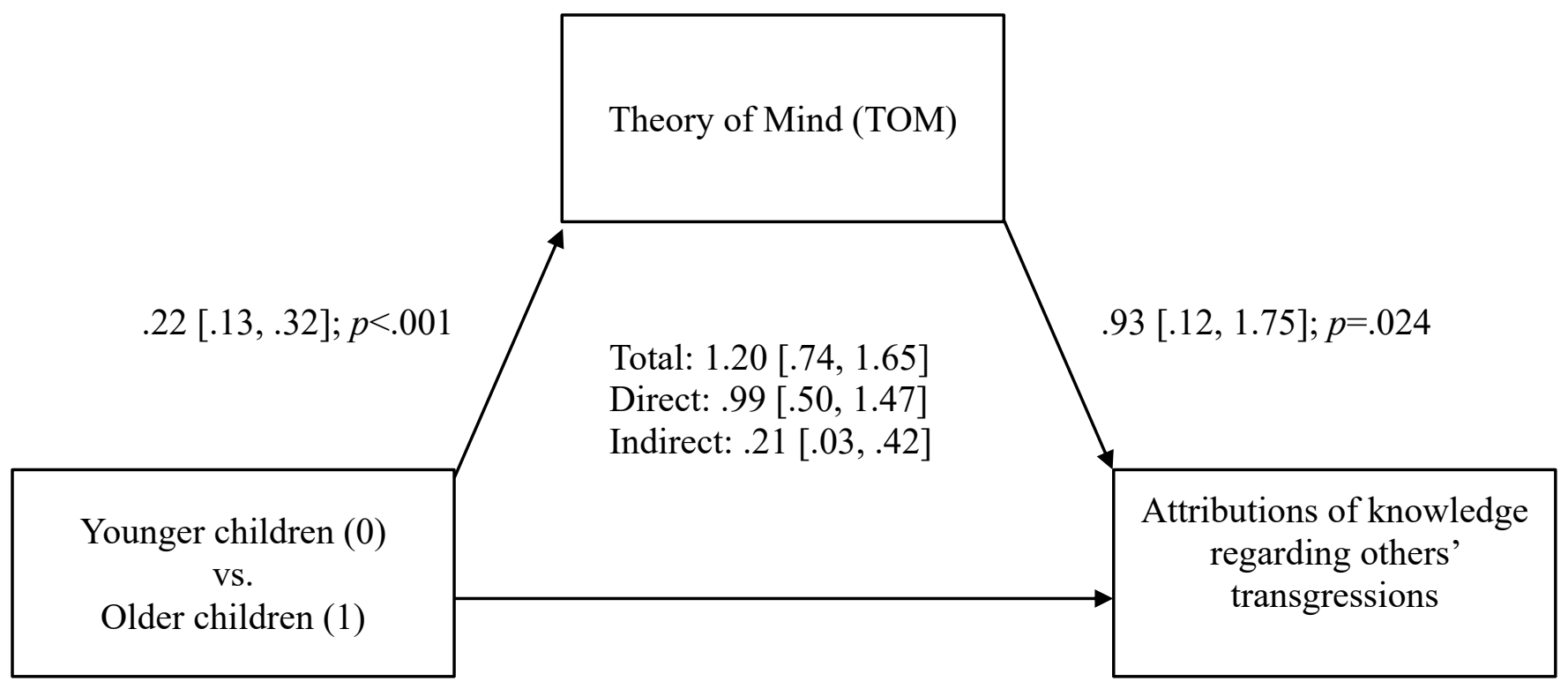

Figure 3. 
MORALIZING GOD CONCEPTS

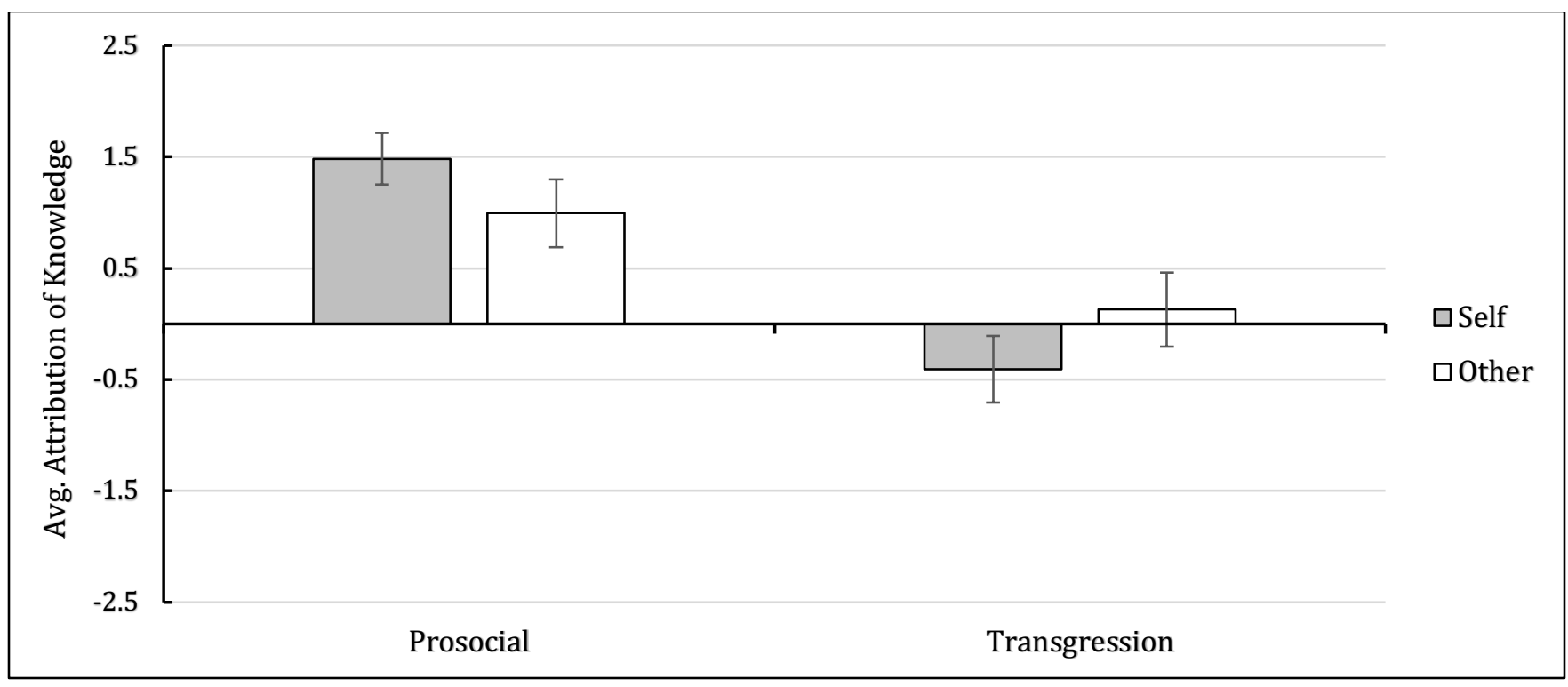

Figure 4. 
MORALIZING GOD CONCEPTS

\section{Figure Captions}

Figure 1. Younger and older children's average attribution of knowledge to God regarding their own and others' transgression. Errors bars represent $95 \%$ confidence intervals.

Figure 2. Mediation model indicating that TOM partially mediated the relation between age group and attribution of knowledge to God regarding participants' own transgressions. The numbers in brackets reflect $95 \%$ confidence intervals.

Figure 3. Mediation model indicating that TOM partially mediated the relation between age group and attribution of knowledge to God regarding others' transgressions. The numbers in brackets reflect $95 \%$ confidence intervals.

Figure 4. Participant's average attribution of knowledge to God for both self and others' prosocial behaviors and transgression. Errors bars represent $95 \%$ confidence intervals. 